http://dx.doi.org/10.1590/1678-49442019v25n3p859

FISCH, Michael. 2018. An Anthropology of the Machine: Tokyo's Commuter Train Network. Chicago: University of Chicago Press. 302 pp.

\section{Eric Macedo}

Programa de Pós-graduação em Antropologia Social, Museu Nacional, Universidade Federal do Rio de Janeiro (PPGAS/MN/UFRJ), RJ, Brasil https://orcid.org/0000-0003-4474-7934

Em uma típica manhã dos dias de semana, os trens urbanos de Tóquio transportam de 300 a 400 pessoas em vagões projetados para carregar 162 . Espremidos no carro lotado, às vezes os passageiros perdem a consciência por falta de oxigênio, permanecendo ainda assim de pé pela pressão dos outros corpos ao seu redor. Para além, contudo, do desconforto com a lotação no interior do carro, a operação em regime de sobrecarga define, em diversas instâncias, a maquinaria do sistema. Em An Anthropology of the Machine, Michael Fisch, professor da Universidade de Chicago, explora este aspecto da rede ferroviária de Tóquio, buscando traçar uma tecnografia da interação humanomáquina de modo a conceber uma teoria da máquina que permita pensar com seres tecnológicos.

A teoria da máquina perseguida por Fisch é tributária principalmente da obra de Gilbert Simondon (1958), tendo como conceito-chave a noção de margem de indeterminação. Há também uma preocupação reiterada ao longo do livro com o emaranhamento ontológico de humanos e máquinas, cujas dimensões éticas são pensadas especialmente por meio do conceito, também simondoniano, de tecnicidade. A intenção é formular um pensamento crítico sobre a máquina que não esbarre em uma condenação simplista da tecnologia como intrinsecamente danosa, em uma idealização nostálgica de um mundo sem máquinas. Porém, o livro tampouco promove uma exaltação ingênua da técnica, lançando luz sobre aspectos éticos e políticos que emergem da relação entre humanos e trens na capital japonesa.

Entre estes aspectos, aparecem questões como a apropriação do sistema de transporte ferroviário por uma estrutura de consumo associada ao sistema de catracas e pagamento de passagens (capítulo 4). A análise ressalta a emergência de uma dinâmica de controle em um contexto de expansão de um "capitalismo extremo". O capítulo 5 é inteiramente dedicado ao fenômeno inquietante do suicídio de passageiros (entre 25 e 30 mil casos por ano) e a forma como o sistema lida com a questão, incluindo as elaborações de sentido em torno do problema ("é sempre um trabalhador assalariado", dizem os habitantes de Tóquio sobre os suicidas).

O capítulo seguinte, que fecha o livro, é construído com base em um acidente de trem em 2005 (conhecido como o "descarrilhamento de Amagasaki") que deixou mais de cem vítimas fatais e levantou um debate público sobre a questão do risco e da confiança em sistemas técnicos. O mesmo problema seria retomado com mais urgência após o acidente de Fukushima alguns anos mais tarde. An Anthropology of the Machine é, de fato, escrito sob a sombra do acidente nuclear, que traz à luz a necessidade de entender a relação humano-máquina em seus aspectos éticos, no contexto de construção da vida coletiva.

Destacam-se ainda os casos frequentes de abuso sexual enfrentado por mulheres nos vagões lotados. 
Pouco notificados, os casos são estimulados por propagandas dentro dos trens com imagens de mulheres sexualizadas, que contribuem para a continuidade de um imaginário do trem como espaço privilegiado de fantasias sexuais masculinas (capítulo 2). A atenção do autor dirige-se aqui, como em outros momentos - na análise do silêncio reinante no trem lotado, por exemplo - para uma descrição detalhada das interações entre humanos tendo o sistema de trens não apenas como meio e mediador, mas como termo fundamental da relação.

É nos capítulos 1 e 3 que Fisch elabora mais profundamente a noção central do livro, em torno do conceito de margem de indeterminação. A noção é trabalhada tendo em vista o modo como os intervalos entre os trens é organizado pela rede ferroviária funcionando em situação de sobrecarga, mas expande-se como peça central do livro, permitindo refletir sobre as diversas instâncias em que relações humano-máquina se encadeiam neste contexto. O destaque dado à ideia faz dela o plano privilegiado para a compreensão da relação em questão: de fato, é como se a interação entre humanos e máquinas se constituísse a partir desta margem.

O sistema consegue operar sobrecarregado, argumenta Fisch, não por meio de um aumento em precisão ou eficiência tecnológica, mas como efeito da expansão da margem de indeterminação da rede: diminui-se o grau de interação roteirizada entre as partes do sistema, permitindo uma sintonização fina das relações. Esta abertura cria flexibilidade para microajustamentos entre os componentes, possibilitando que o sistema se adapte a contextos em variação, ao invés de basear-se em relações duras, prefixadas.
O Japão enfrentou um aumento persistente na demanda por transporte ferroviário desde as primeiras décadas do século XX. Há mais de um século o sistema no país opera sobrecarregado, e o problema não poderia ser resolvido simplesmente aumentando o número de trens em circulação. Mesmo que os trens circulassem com absoluta pontualidade $\mathrm{e}$ no mínimo intervalo, e que toda a massa de passageiros fosse perfeitamente treinada a entrar nos vagões da maneira mais rápida e ordenada possível (um delírio fascista, nota Fisch), ainda assim a demanda não poderia ser suprida inteiramente.

A questão estaria então em refinar intervalos, com uma série de estratégias para melhorar a capacidade do sistema: diminuir, por exemplo, o tempo necessário para as viradas dos trens nas estações finais ou sua permanência em cada estação. Os ajustes, acompanhando a demanda crescente, são frutos de novos aspectos técnicos associados a um esforço de sintonia fina dos intervalos. A partir de 1957 foram introduzidos trens de alta performance que permitem uma prática nomeada pelos condutores de "direção de recuperação" (kaifuku unten). A possibilidade de aceleração e desaceleração rápidas na entrada ou na saída das estações abriu uma margem para recuperar o tempo de permanência nas plataformas. Não se trata simplesmente de acelerar o trem, mas de ajustar os tempos de modo a que todo o sistema de intervalos (daiya) funcione a contento.

O capítulo 3 descreve a introdução de um novo sistema de controle em 1996, que provoca uma mudança mais radical na forma como a rede ferroviária é estruturada. De uma busca por maior centralização, passa-se a um controle descentralizado dos trens. Isto permite deslocar a ideia de capacidade do sistema: 
ao invés de aumentar a capacidade, o que se tem como alvo agora é uma operação com capacidade ilimitada, ou onde a questão da capacidade ou do limite já não se colocam. O novo sistema não produziu mudanças notáveis em relação a menos lotação ou mais velocidade em cada deslocamento, porém, ele permitiu à rede lidar com um aumento súbito dos casos de suicídio, dotando-a de flexibilidade em face de eventos que exercem forças de desordenação do sistema.

O princípio subjacente ao novo sistema ecoa aspectos das "teorias da emergência" desenvolvidas na interseção entre ciências biológicas, a física e a informática. A ideia central que o sustenta é a de que a "irregularidade é regular". Princípio desenvolvido para pensar sobre organismos vivos, ele dotaria o sistema maquínico da possibilidade de devir-orgânico (becoming-organic) ao incrementar o grau de concretização (outra expressão simondoniana) do sistema ferroviário ao mesmo tempo em que expande sua margem de indeterminação.

Já em Simondon, a margem de indeterminação de uma máquina manifesta-se (mas não apenas) por assim dizer em "janelas" de interação com outros seres técnicos e com o humano. Apresenta-se em conexões entre máquinas, como cabos e transformadores, mas também em displays, manivelas, botões. E, talvez mais intensamente, naquelas instâncias que não correspondem apenas a uma afetação mútua do tipo causa-efeito entre máquinas, mas que exigem um processo de transdução só possível em um ser vivo - a necessidade de pensar. Em aberturas, assim, para um funcionamento não automatizado.

A vida, para Simondon, possui uma margem de indeterminação muito maior que a máquina. A vida é também rica em concretude, enquanto a máquina a adquire progressivamente conforme se individualiza. O grau de concretização de uma máquina é proporcional à sua coerência interna, ao acabamento de seu funcionamento, que a individua e permite a sua autoorganização. Quanto mais concreta é uma máquina, mais independente de seu meio artificial (o laboratório em que foi criada, por exemplo) ela é, mas ao mesmo tempo mais ela é imiscuída em seu próprio ambiente técnico, mais relações ela tem com outras máquinas e seres não maquínicos - maior é o seu grau de tecnicidade.

Estão em jogo, portanto, como que duas dimensões da relação organismos vivos/seres tecnológicos: uma que é do domínio de sua individuação e que diz respeito a um devir-orgânico da máquina; e outra correspondente à interação entre humanos e máquinas que o funcionamento de qualquer conjunto técnico pressupõe. Fisch trabalha estas duas dimensões em diferentes momentos. De um lado, o devir-orgânico do sistema de trens oferece matéria interessante para pensar a formação de coletivos tecnológicos adequados para lidar com as crises do Antropoceno, mas também seus perigos diante de um capitalismo configurado ele mesmo em redes descentralizadas e capaz de inovar em sua capacidade de captura. De outro, a interação entre máquinas e humanos, mediada ou produzida a partir da margem de indeterminação, é tomada como um processo relacional que tende à co-constituição entre os dois termos, o que poderia levar a um questionamento da dicotomia inicial humano/máquina.

Este último ponto exige uma elaboração mais extensa, à qual The Anthropology of the Machine não se dispõe. O próprio conceito de máquina poderia ser retrabalhado com base nas 
formulações iniciais de Simondon, permitindo uma compreensão mais ampla de conjuntos técnicos formados em emaranhamentos ontológicos entre seres humanos e tecnológicos. Correlativamente, é também o fenômeno humano que se evidencia em sua indiscernibilidade em relação às máquinas que o constituem e das quais ele mesmo é parte.

\section{Referência bibliográfica}

FISCH, Michael. 2018. An Anthropology of the Machine: Tokyo's Commuter Train Network. Chicago: University of Chicago Press. 302 pp.

SIMONDON, Gilbert. 1958. Du mode d'existence des objets techniques. Paris: Aubier. 